\title{
Protein tyrosine phosphatase receptor delta acts as a neuroblastoma tumor suppressor by destabilizing the aurora kinase a oncogene
}

\author{
Maria Meehan ${ }^{1,2 \dagger}{ }^{+}$, Laavanya Parthasarathi ${ }^{1,2 \dagger}$, Niamh Moran ${ }^{1}$, Caroline A Jefferies ${ }^{1}$, Niamh Foley ${ }^{1,2}$, Elisa Lazzari ${ }^{1}$ \\ Derek Murphy ${ }^{3}$, Jacqueline Ryan ${ }^{1,2}$, Berenice Ortiz ${ }^{4}$, Armida W M Fabius ${ }^{4}$, Timothy A Chan ${ }^{4}$ and \\ Raymond L Stallings ${ }^{1,2^{*}}$
}

\begin{abstract}
Background: Protein tyrosine phosphatase receptor delta (PTPRD) is a member of a large family of protein tyrosine phosphatases which negatively regulate tyrosine phosphorylation. Neuroblastoma is a major childhood cancer arising from precursor cells of the sympathetic nervous system which is known to acquire deletions and alterations in the expression patterns of PTPRD, indicating a potential tumor suppressor function for this gene. The molecular mechanism, however, by which PTPRD renders a tumor suppressor effect in neuroblastoma is unknown.

Results: As a molecular mechanism, we demonstrate that PTPRD interacts with aurora kinase A (AURKA), an oncogenic protein that is over-expressed in multiple forms of cancer, including neuroblastoma. Ectopic upregulation of PTPRD in neuroblastoma dephosphorylates tyrosine residues in AURKA resulting in a destabilization of this protein culminating in interfering with one of AURKA's primary functions in neuroblastoma, the stabilization of MYCN protein, the gene of which is amplified in approximately 25 to $30 \%$ of high risk neuroblastoma.

Conclusions: PTPRD has a tumor suppressor function in neuroblastoma through AURKA dephosphorylation and destabilization and a downstream destabilization of MYCN protein, representing a novel mechanism for the function of PTPRD in neuroblastoma.
\end{abstract}

Keywords: PTPRD, AURKA, MYCN, Neuroblastoma, Tumor suppressor

\section{Background}

Protein tyrosine phosphatase receptor delta (PTPRD) is an important regulator of axon growth and guidance and is highly expressed in the central nervous system where it functions as a transmembrane homophilic neuronal cell adhesion molecule [1]. PTPRD undergoes a high frequency of hemizygous/homozygous deletions in multiple forms of cancer, which are often intragenic in nature, indicating a potential tumor suppressor function [2-8]. Additional mechanisms leading to PTPRD inactivation include promoter region hypermethylation, point mutations and aberrant splicing [6,9-12].

\footnotetext{
* Correspondence: rstallings@rcsi.ie

† Contributed equally

'Department of Molecular and Cellular Therapeutics, Royal College of

Surgeons in Ireland, Dublin 2, Dublin, Ireland

Full list of author information is available at the end of the article
}

Neuroblastoma is derived from primitive cells of the sympathetic nervous system, and is the most common extracranial solid tumor in children accounting for $15 \%$ of all childhood cancer deaths [13]. These tumors are particularly noted for extensive heterogeneity in clinical behaviour, ranging from spontaneous regression to aggressive clinical course and death from disease. Notably, amplification of the $M Y C N$ transcription factor is one of the most powerful adverse prognostic factors in neuroblastoma [14] and we have previously demonstrated that PTPRD is expressed at significantly lower levels in $M Y C N$ amplified neuroblastoma relative to non-MYCN amplified tumors [10]. In addition, PTPRD mRNA expression is higher in normal adrenal fetal neuroblasts, the cell of origin of neuroblastoma, relative to unfavourable neuroblastoma tumors, indicating that PTPRD down-regulation might be an important step in 
the development of these tumors [7,10]. Multiple mechanisms appear to exist for the down-regulation of $P T P R D$ in neuroblastoma, including intragenic microdeletions which can include coding sequence, or in some instances be restricted to non-coding exons of an extended 5' UTR [5]. Aberrant splicing of the 5' UTR also has been noted in neuroblastoma cell lines and primary tumors, which could potentially cause destabilization of the mRNA sequence [10].

In this report, we demonstrate for the first time that experimental up-regulation of PTPRD in neuroblastoma cell lines significantly decreases cell growth and increases apoptosis. Moreover, we identify aurora kinase $\mathrm{A}$, a serine/threonine kinase oncogene that is up-regulated in many forms of cancer, including high risk neuroblastoma [15], as an interaction partner of PTPRD. We further demonstrate that PTPRD has a tumor suppressor function in neuroblastoma through dephosphorylating and destabilizing AURKA, leading to a downstream decrease of MYCN protein. Our findings represent a novel mechanism of action for the function of PTPRD in neuroblastoma.

\section{Results}

PTPRD functions as a tumor suppressor in neuroblastoma In order to further examine the possibility that PTPRD acts as a tumor suppressor gene in neuroblastoma, we initially analyzed the levels of PTPRD mRNA transcripts in a set of 88 neuroblastoma tumors using the R2: microarray analysis and visualization platform (http://r2. amc.nl) (University of Amsterdam). Lower than median PTPRD mRNA levels were significantly associated with both poor relapse free and overall patient survival, consistent with PTPRD having a tumor suppressor function (Figure $1 \mathrm{~A}$ and $1 \mathrm{~B}$ ).

We then sought to determine the effects of PTPRD over-expression in neuroblastoma cell lines that have only minimally detectable PTPRD mRNA transcripts. Kelly cells (MYCN amplified) have a homozygous deletion in the PTPRD 5' UTR [5], while SHSY-5Y (MYCN non-amplified) has a 5' UTR that was generated by exon skipping [10]. Although there is no evidence for deletion or aberrant splicing of PTPRD in CHP212 (MYCN amplified), endogenous mRNA transcripts are nevertheless at very low levels. These three cell lines were transfected with a wild type PTPRD V5-tagged cDNA clone [6] to determine the impact of over-expression on cell growth. Ectopic expression of PTPRD at mRNA and protein level was validated by TaqMan qPCR and by Western blot analysis (for a V5 epitope tag) (Additional File 1). Ectopic up-regulation of PTPRD resulted in a significant decline in cell growth in all three cell lines (Figure 2A-C). To determine if the phosphatase activity of PTPRD is required to have anti-proliferative effects

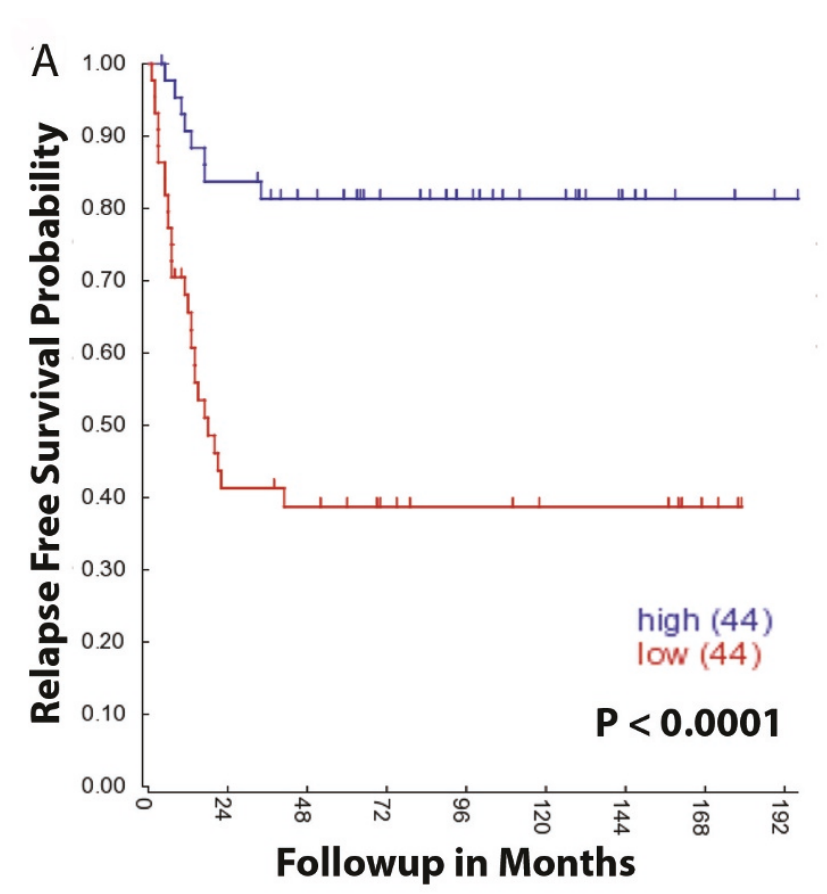

B

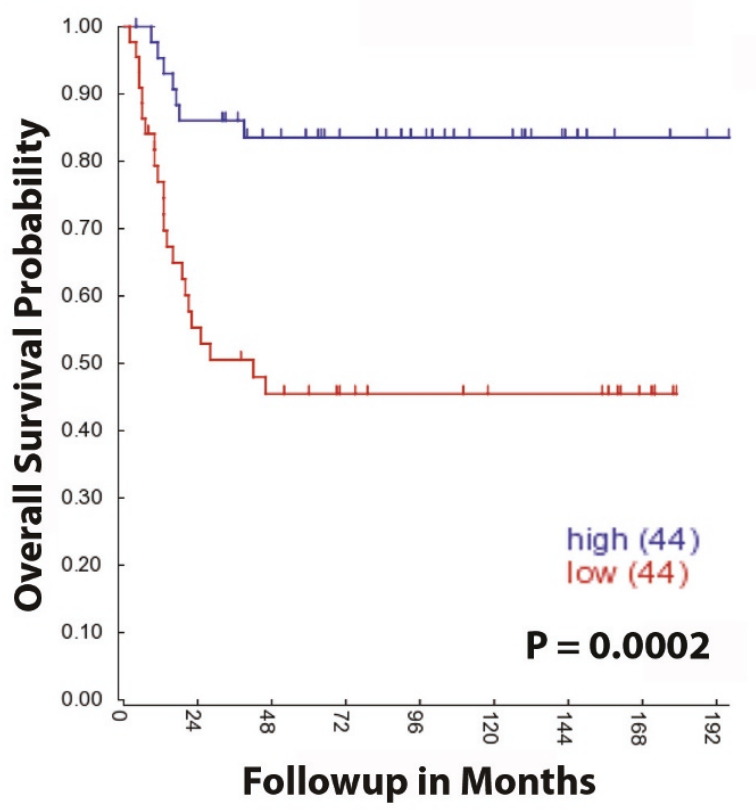

Figure 1 Kaplan Meier survival curves demonstrating the relationship between patient survival and PTPRD gene expression using the R2: microarray analysis and visualization platform (http://r2.amc.nl). (A) is relapse free survival and (B) is overall survival where low expression is $<$ median ( $n=44$ (tumors) and high expression is $>$ median ( $n=44$ tumors). 

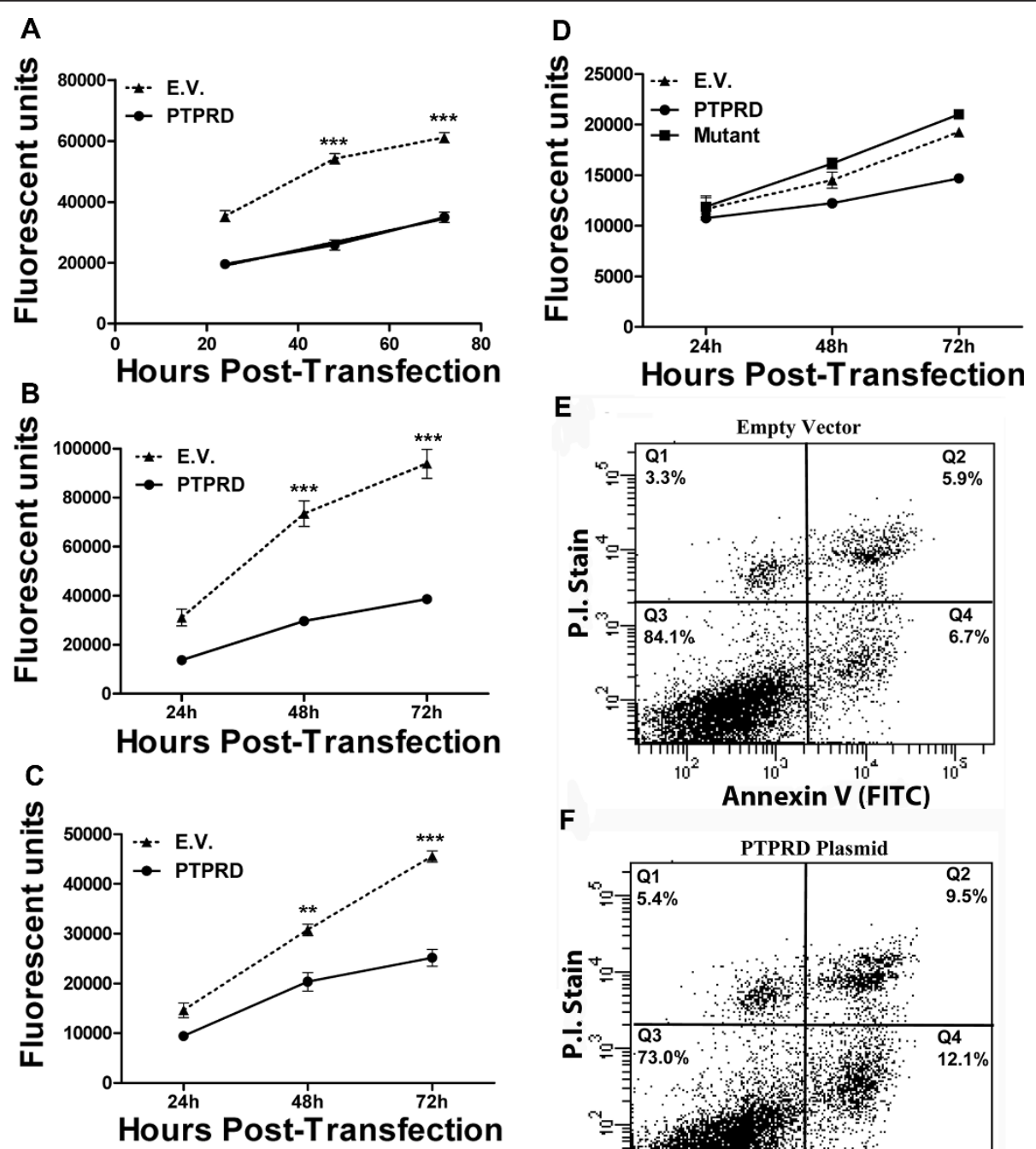

E

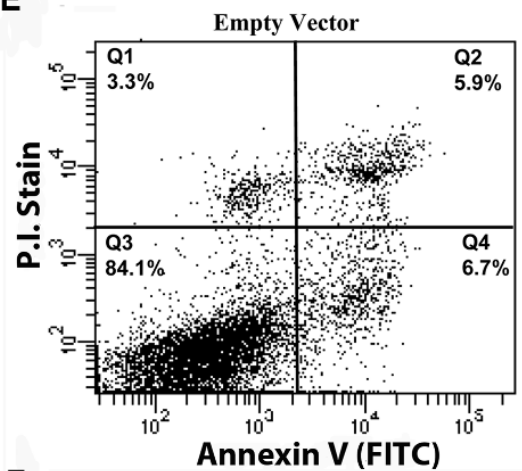

$\mathbf{F}$

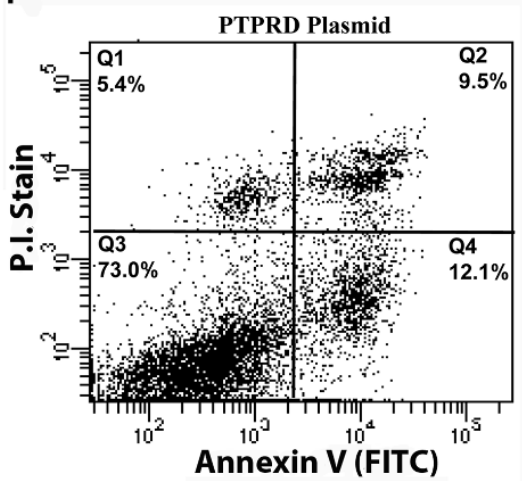

Figure 2 Ectopic over-expression of wild type PTPRD suppresses the growth of human neuroblastoma cell lines by inducing cell apoptosis. (A) SHSY5Y (B) Kelly and (C) CHP-212 cells were transfected with PTPRD cDNA or empty vector (pcDNA3.1-V5) and were analysed by a Cyquant assay at 24, 48 and 72 h. All graphs report mean \pm S.E.M., $n=3,{ }^{* *} p<0.01,{ }^{* * *} p<0.001$. (D) Kelly cells transfected with either empty vector or an expression plasmid containing PTPRD with a mutated phosphatase domain. PTPRD induced apoptosis was demonstrated by FACS analysis of annexin- $V$ staining. Kelly cells were transfected with empty vector (E) or PTPRD cDNA (F). Cells were harvested $72 \mathrm{~h}$ post transfection. PI staining of DNA represents necrotic cells (upper left quadrant). Annexin $V$ staining indicates cells that are early apoptotic (bottom right quadrant). Double stained cells (upper right quadrant) indicate cells in late apoptosis. Percentages of cells in each quadrant are shown.

on cell lines, a mutant form of PTPRD containing a cancer specific mutation, Q1481X, that results in a truncated protein product lacking a functional C-terminal phosphatase domain, was transfected into Kelly cells. Over-expression of this PTPRD mutant did not lead to a significant decrease in cell growth compared to empty vector transfected cells (Figure 2D), indicating that a functional phosphatase domain is required. FACS analysis of Kelly cells transfected with either wild type PTPRD or empty vector, followed by staining with propidium iodide and staining for Annexin $\mathrm{V}$, revealed that
PTPRD up-regulation resulted in a median 1.7 fold increase in apoptosis relative to empty vector control (Figure 2E, F).

\section{Identification of proteins that interact with PTPRD}

Taken together, all available evidence indicates that PTPRD is a neuroblastoma tumor suppressor, but the molecular mechanism(s) is unknown, as only a small number of PTPRD interacting partners have been identified. PTPRD is known to interact with the metastasis suppressor protein 1 (MTSS1), liprin-alpha 1 (LAR), and 
signal transducer and activator of transcription 3 (STAT3) $[6,16,17]$. In order to discover new potential substrates for PTPRD in the context of neuroblastoma, we used a commercially available protein-protein interaction array containing 9,400 proteins. A biotinylated PTPRD protein was used to probe the protein microarray to detect potential interaction partners. This experiment was conducted in duplicate (biological replicates as two different biotinylated PTPRD baits were used). The consensus interacting proteins with above-background signal are listed in Table 1.

One of the top scoring proteins on the PTPRD interaction arrays was aurora kinase A (AURKA), a serine/ threonine kinase that is involved in microtubule formation and stabilization at the spindle pole during chromosome segregation [18]. In neuroblastoma, high AURKA expression is associated with poor patient survival [15], so that the interaction of a tumor suppressor with AURKA was of immediate interest. In order to confirm an in vivo interaction between PTPRD and AURKA in neuroblastoma, protein extract isolated from Kelly cells transfected with either the V5-tagged PTPRD cDNA or empty vector was immunoprecipitated with a V5 epitope antibody. As illustrated in Figure 3A, western blotting demonstrated that V5-tagged PTPRD was immunoprecipitated from cells, with a clear band of approximately $85 \mathrm{kDa}$ being detected compared with empty vector control. The PTPRD pro-protein (220 $\mathrm{kDa}$ ) is cleaved intracellularly into two subunits of 150 $\mathrm{kDa}$ (E-subunit) and $85 \mathrm{kDa}$ (P-subunit) [19]. This process is called "ectodomain shedding" and affects a number of transmembrane proteins. The 150-kDa E-subunit is predicted to contain the three Ig-like and eight FNIII-like domains, whereas the $85-\mathrm{kDa}$ P-subunit contains a short ectodomain segment, the transmembrane peptide, and the intracellular PTPase domains and is expressed in the membrane of the cell. The $150 \mathrm{kDa}$ band is not visualized because it has lost the V5 epitope tag. Western blot probed with AURKA antibody indicates that AURKA co-immunoprecipitates with the V5 epitope pulled down with the V5 antibody, confirming a PTPRD-AURKA interaction in vivo (Figure 3B).

\section{PTPRD destabilizes AURKA by dephosphorylating tyrosine} sites

Having confirmed a PTPRD-AURKA interaction, we next investigated whether AURKA is a potential substrate for PTPRD. Within the catalytic domain of AURKA, there are a number of conserved tyrosine phosphorylation sites (Y148, Y199, Y197, Y212) [20]).

Table 1 Protein Interaction Array Results

\begin{tabular}{|c|c|c|c|c|c|c|}
\hline Gene ID & Array ID & Z-score $1 A^{*}$ & Z-score 1B & Z-score $2 A$ & Z-score 2B & Mean Score \\
\hline SLAIN2 & BC031691.2 & 15.6862 & 14.84417 & 26.53102 & 26.53143 & 20.898205 \\
\hline AURKA & PV3612 & 17.81632 & 17.54567 & 23.21736 & 21.82452 & 20.1009675 \\
\hline NEK1 & PV4202 & 11.32571 & 10.6591 & 26.53388 & 26.53388 & 18.7631425 \\
\hline PLK1 & PV3501 & 10.43356 & 7.98767 & 26.28537 & 24.45825 & 17.2912125 \\
\hline EPHA8 & PV3844 & 13.1952 & 11.49612 & 21.98299 & 21.87788 & 17.1380475 \\
\hline TBK1 & PV3504 & 12.278 & 11.42595 & 21.61471 & 18.89013 & 16.0521975 \\
\hline CSNK1D & PV3665 & 6.59933 & 4.8401 & 23.86103 & 21.60616 & 14.226655 \\
\hline CSNK1E & PV3500 & 4.19855 & 3.59711 & 15.00776 & 14.78818 & 9.3979 \\
\hline MARK2 & PV3878 & 5.18092 & 4.76492 & 11.28101 & 13.46825 & 8.673775 \\
\hline STK22B & PV3622 & 4.70477 & 4.58448 & 9.74924 & 10.31917 & 7.339415 \\
\hline SMTNL2 & NM_198501.1 & 8.20319 & 7.9576 & 6.70486 & 6.47999 & 7.33641 \\
\hline PAK6 & PV3502 & 6.12319 & 4.86015 & 9.65432 & 8.0142 & 7.162965 \\
\hline NEK2 & PV3360 & 3.79759 & 3.28135 & 10.46746 & 10.817 & 7.09085 \\
\hline DDX17 & NM_030881.2 & 11.17033 & 10.22806 & 3.26491 & 3.22825 & 6.9728875 \\
\hline NEK6 & PV3353 & 7.72705 & 7.69697 & 5.83062 & 5.50919 & 6.6909575 \\
\hline ABLIM1 & BC002448.2 & 7.49649 & 4.08829 & 7.04747 & 7.37379 & 6.50151 \\
\hline SCEL & BC020726.1 & 4.70978 & 2.7651 & 10.60149 & 5.45623 & 5.88315 \\
\hline BMX & PV3371 & 5.37138 & 5.07566 & 5.66807 & 4.98611 & 5.275305 \\
\hline MATK & PV3370 & 3.42168 & 3.27633 & 6.37244 & 7.68829 & 5.189685 \\
\hline IRS1 & BC053895 & 5.80241 & 5.78237 & 3.98394 & 2.59843 & 4.5417875 \\
\hline DDX54 & BC001132.1 & 3.27132 & 2.99065 & 3.27469 & 3.16062 & 3.17432 \\
\hline
\end{tabular}

* $1 \mathrm{~A}$ and $1 \mathrm{~B}$ are technical replicates using the same protein bait. $2 \mathrm{~A}$ and $2 \mathrm{~B}$ are technical replicates using a second bait are therefore biological replicates of $1 \mathrm{~A}$ and $1 \mathrm{~B}$. 


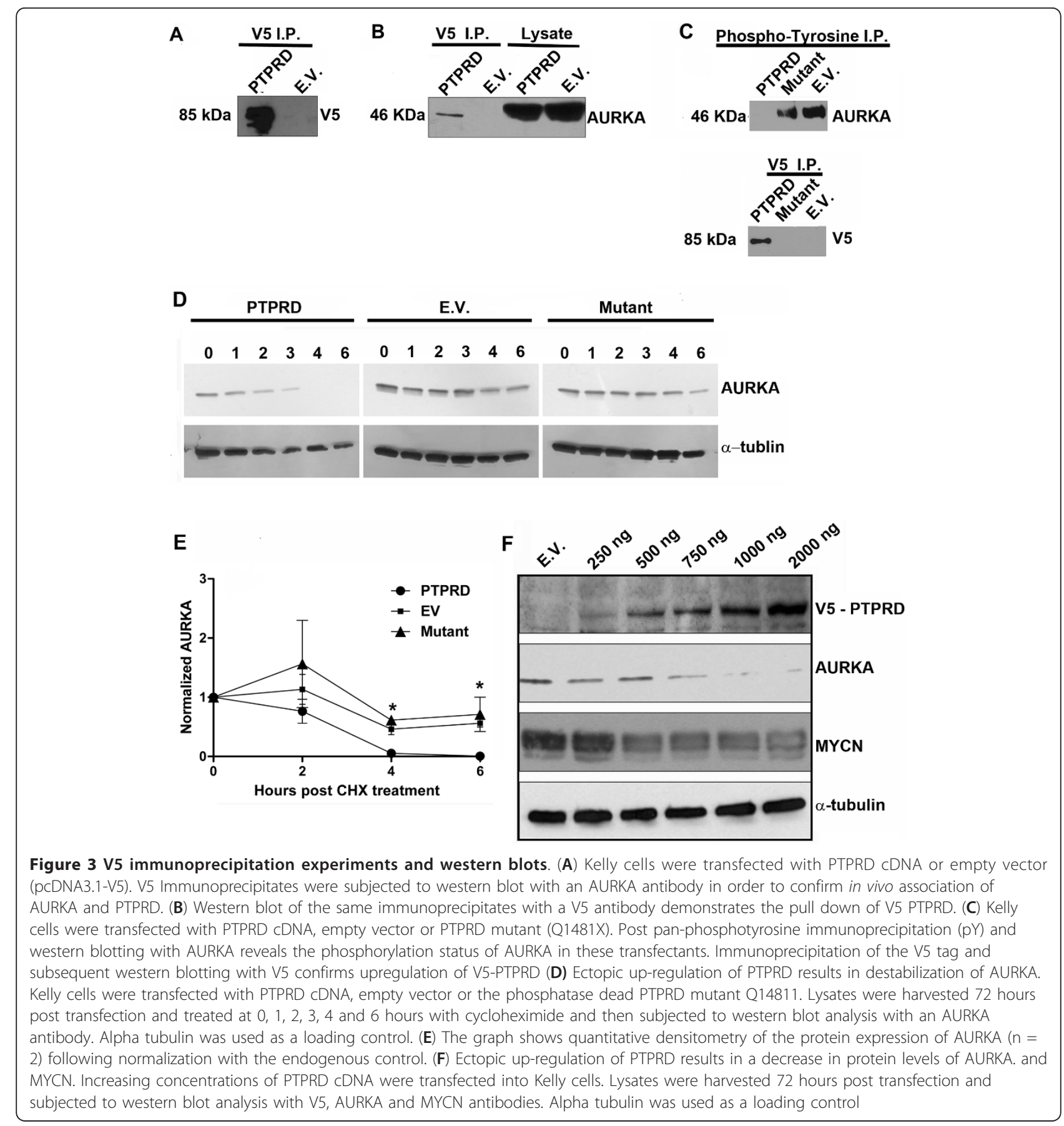

Immunoprecipitation of tyrosine phosphorylated proteins with a pan-phosphotyrosine agarose conjugate and subsequent western blotting with an AURKA antibody revealed an abolishment of AURKA tyrosine phosphorylation in PTPRD cDNA transfected cells compared to phosphatase dead mutant or empty vector control transfectants, confirming the mechanism of action of PTPRD (Figure 3C). In addition to deactivating AURKA, ectopic over-expression of PTPRD also leads to a decrease in protein stability of AURKA. After 4 hours of cycloheximide treatment, there is a significant difference in the decay of AURKA in the PTPRD transfected cells compared to empty vector (EV) or phosphatase dead mutant (Figure 3D, E). qPCR analysis of AURKA mRNA at 48 hours post PTPRD transfection indicated no significant change relative to negative control, confirming that the AURKA decrease is post-transcriptional (Additional File 2A). 
A critical function of AURKA in neuroblastoma is to regulate MYCN protein stability by sequestering MYCN from ubiquitin-mediated proteolytic degradation mediated by the FBXW7 ubiquitin ligase [21], leading us to hypothesize that a down-stream effect of ectopic over-expression PTPRD in neuroblastoma cells would be the destabilization of MYCN. As illustrated in Figure $3 F$, MYCN protein levels are also decreasing as a consequence of PTPRD ectopic over-expression. The decrease in $\mathrm{MYCN}$ protein is due to a post-transcriptional mechanism, as there is no change in MYCN mRNA (Additional File 2B).

\section{Discussion}

In this report we demonstrate a novel in vivo interaction between the tumor suppressor PTPRD and the oncogenic AURKA protein in neuroblastoma. Furthermore, to our best knowledge, this is the first report to demonstrate dephosphorylation of tyrosine residues in AURKA leading to its subsequent destabilization. The identification of AURKA as a novel target of PTPRD mediated dephosphorylation adds to a growing list of substrates for this tumor suppressor. Activity of AURKA is also regulated by phosphorylation of Thr288 in a cell cycle dependent manner [22]. Constitutive phosphorylation on Ser51 of AURKA has also been shown to be associated with its over-expression and protein stabilization, preventing protein degradation mediated by the ubiquitin-proteasome system [23] and it is likely that constitutive phosphorylation of tyrosine residues in AURKA also prevent its degradation. AURKA destabilization also has the down-stream effect of destabilizing MYCN, consistent with prior findings by Otto et al. [21]. Thus, PTPRD is likely to have a tumor suppressor function in any type of cancer with MYCN amplification, including other pediatric cancers such as medulloblastoma and rhabdomyosarcoma, or in adult tumors that are dependent on high AURKA levels.

MYCN directly up-regulates AURKA by binding to its promoter region, forming an auto regulatory feedback loop [21]. As previously mentioned, PTPRD expression is significantly lower in MYCN amplified tumors relative to non-MYCN amplified tumors [10], indicating that MYCN might be directly repressing PTPRD in order to maintain AURKA levels. However, analysis of a previously published data set on MYCN binding sites in neuroblastoma cell lines indicated that MYCN does not bind to the PTPRD promoter region [24,25], revealing that down-regulation of PTPRD in $M Y C N$ amplified tumors is an indirect effect.

Along with AURKA, a number of other proteins scored highly in our protein-protein interaction arrays, including SLAIN2, and two serine/threonine kinases, NEK2 and PLK1.
SLAIN2 has recently been shown to play an important role in the microtubule complex by controlling microtubule dynamics and organization [26]. NEK2 is an integral component of the mitotic spindle-assembly checkpoint which is necessary for proper chromosome segregation during metaphase-anaphase transition [27], while PLK1 is an early trigger for G2/M transition [28]. Intriguingly, one of the primary functions of AURKA is the activation of PLK1 by direct phosphorylation of Thr210 [29], and high expression of PLK1 is also significantly associated with high-risk neuroblastoma and unfavourable patient outcome [30]. Inhibition of PLK1 protein has an anti-proliferative effect on neuroblastoma cell proliferation [30]. Although the interaction of PTPRD with these proteins requires validation, it seems likely that over-expression of PTPRD should have a pleiotrophic tumor suppressor effect by associating with, and dephosphorylating a number of interacting partners. The recent development of AURKA inhibitors, along with impressive results in pre-clinical models of pediatric cancer, indicate that AURKA could be a therapeutic target of great value in the treatment of neuroblastoma $[31,32]$. PTPRD, as a natural antagonist of AURKA, might be of therapeutic value in cancers where its inactivation is epigentically reversible, such as in instances of promoter region hypermethylation.

\section{Conclusions}

Over-expression of PTPRD in neuroblastoma cell lines results in decreased cell viability through the activation of apoptosis. We further demonstrate a novel PTPRDAURKA protein interaction, and that PTPRD overexpression results in the dephosphorylation and the destabilization of AURKA, along with a down-stream destabilization of MYCN protein. These findings, taken together, indicate a novel mechanism of action for PTPRD as a neuroblastoma tumor suppressor through the inhibition of these important oncogene products.

\section{Methods}

\section{Cell Culture, In Vitro Growth and Apoptosis Assays}

SHSY-5Y and CHP-212 neuroblastoma cell lines were obtained from the American Type Culture Collection, while Kelly was obtained from European Collection of Animal Cell Cultures. All cell lines were validated for the presence of previously published genomic imbalances using aCGH. Culture media was supplemented with $10 \%$ FBS.

Cells were transfected with $2 \mu \mathrm{g}$ PTPRD cDNA, empty vector (pcDNA3.1-V5) or phosphatase dead mutant PTPRD (Q14811) using lipofectamine 2000 reagent according to

the manufacturer's instructions (Invitrogen, Carlsbad, $\mathrm{CA}$ ) and were analysed by a Cyquant assay (Invitrogen) 
at 24, 48 and $72 \mathrm{~h}$. PTPRD induced apoptosis was demonstrated by FACS analysis of annexin-V staining. Kelly cells were transfected with empty vector or PTPRD cDNA. Cells were harvested $72 \mathrm{~h}$ post transfection and apoptosis was quantified using the FITC Annexin-V Apoptosis Detection Kit I (BD Pharmingen, San Diego, CA, USA). Experiments were performed in triplicate to quantify apoptosis by phosphatidylserine (PS) externalization.

\section{Immunoprecipitation experiments}

Kelly cells (80-90\% confluence) were transfected with 2 $\mu \mathrm{g}$ PTPRD cDNA or empty vector (pcDNA3.1-V5) in $100 \mathrm{~mm}$ dishes. After $24 \mathrm{~h}$ transfection, cells were incubated in a RIPA buffer (Sigma-Aldrich, Arklow) containing complete protease inhibitor mixture. The lysates were cleared by centrifugation for $20 \mathrm{~min}$ at $14,000 \times \mathrm{g}$ and then subjected to immunoprecipitation with either anti-V5 agarose affinity beads (Sigma-Aldrich) for co-IP experiments or $4 \mathrm{G} 10^{\circledR}$ Platinum, anti-phosphotyrosine agarose conjugate (Millipore) for pan-tyrosine IP experiments, and then incubated at $4 \mathrm{C}$ for $2 \mathrm{~h}$. The beads were washed five times with RIPA buffer, incubated in laemmli sample buffer and heated to $95 \mathrm{C}$ for five mins. Resultant samples were separated by SDS-PAGE and were analysed by western blotting.

\section{Western blotting}

Cells were washed with PBS and lysed at $4 \mathrm{C}$ for $20 \mathrm{~min}$ using RIPA buffer containg phosphatase and protease inhibitors. Lysates were centrifuged for $20 \mathrm{~min}$ at 14,000 $\times \mathrm{g}$ and resultant protein extracts were separated by SDS-PAGE and blotted onto PVDF membranes. Antibodies used were as follows: anti-V5 (Invitrogen), antiAURKA (Sigma), anti-MYCN (Santa Cruz) and antialpha tubulin (Abcam). Secondary antibodies were horseradish peroxidise-conjugated rabbit anti-mouse (Abcam) or goat anti-rabbit (Cell Signaling Technology). Reactive proteins were visualized by chemiluminescence with ECL (Thermo).

\section{PTPRD Interaction arrays}

Purified PTPRD protein (99\% pure, mass spectrum verified) (Clone ID 8613c5BCt10p1, protein sequence 12011495) was biotinylated and quantitated in duplicate using the Invitrogen FluoReporter ${ }^{\circledR}$ Biotin Quantitation Assay Kit. The array control protein (biotinylated calmodulin kinase) supplied as part of the Invitrogen protein interaction kit was used to probe the Protoarray ${ }^{\circledR}$ control protein microarray to validate assay conditions. Biotinylated PTPRD baits (two biological replicates) were then used to probe the Invitrogen ProtoArray ${ }^{\circledR}$ Protein Microarray Kit for biotinylated proteins Version
4 in order to detect potential interaction partners. The results were analyzed using the Protoarray prospector ${ }^{\circledR}$ package. The consensus hits (hits that are above the back ground signal in both the experiments) along with their Z-scores are listed in Table 1. A Z-Score indicates how far and in what direction the value of an individual data point in a population falls from the mean in units of standard deviations. ProtoArray ${ }^{\circledR}$ Prospector collects all the signals from the proteins on a microarray, calculates the mean value and standard deviation, and then calculates a Z-Score corresponding to the signal from each feature.

\section{Cycloheximide half-life experiments}

Kelly cells (80-90\% confluence) were transfected with 2 $\mu$ g PTPRD cDNA, empty vector (pcDNA3.1-V5) or PTPRD mutant (Q1481X) in $100 \mathrm{~mm}$ dishes. After $72 \mathrm{~h}$ transfection, cells were incubated in a RIPA buffer (Sigma-Aldrich, Arklow) containing complete protease inhibitor mixture. Cells were treated with $1 \mu \mathrm{l}$ of a 20 $\mathrm{mg} / \mathrm{ml}$ stock solution of cycloheximide (Sigma-Aldrich) 5 min prior to starting the indicated time course, and cells were collected at the indicated points. Quantification of western blots was performed by densitometry using GelEval (FrogDance Software). Normalization for loading differences was achieved by dividing the densitometry values for individual bands by the densitometry values for alpha-tubulin in the same lane.

\section{Additional material}

Additional File 1: Expression of PTPRD (A) mRNA and (B) protein following transfection of Kelly cells with increasing concentrations of PTPRD cDNA. mRNA was extracted at 24 hours and qPCR was performed. Lysates were harvested at $48 \mathrm{~h}$ and subjected to SDS PAGE and western blot analysis with a monoclonal antibody to the V5 epitope tag or alpha tubulin. All experiments were performed in triplicate.

Additional File 2: (A) Expression of AURKA mRNA 48 hours post PTPRD expression. Either $1 \mu \mathrm{g}$ of PTPRD or empty vector (E.V.) were transfected into Kelly cells. mRNA was extracted at 48 hours and qPCR was performed. The figure is representative of four independent experiments and E.V. is set as 1.0. (B) Expression of MYCN mRNA 48 hours post PTPRD expression. Either $1 \mu \mathrm{g}$ of PTPRD or empty vector (E.V.) were transfected into Kelly cells. mRNA was extracted at 48 hours and qPCR was performed. The figure is representative of four independent experiments and E.V. is set as 1.0.

\section{Abbreviations}

AURKA: aurora kinase A; PTPRD: Protein Tyrosine Phosphatase Receptor Delta; IP: immunoprecipitation

\section{Acknowledgements}

This work was supported in part by the Association of International Cancer Research (07-0033) and the Children's Medical and Research Foundation. We acknowledge the New York SGX Research Center for Structural Genomics (NYSGXRC, NIGMS Grant U54 GM074945) for providing samples of purified PTPRD protein. 


\section{Author details}

'Department of Molecular and Cellular Therapeutics, Royal College of Surgeons in Ireland, Dublin 2, Dublin, Ireland. 'National Children's Research Centre, Our Lady's Children's Hospital, Dublin 12, Dublin, Ireland. ${ }^{3}$ Centre for Human Proteomics, Royal College of Surgeons in Ireland, Dublin 2, Dublin, Ireland. ${ }^{4}$ Department of Radiation Oncology, Memorial Sloan-Kettering Cancer Center, 1275 York Avenue, New York, NY 10065, USA.

\section{Authors' contributions}

$M M, L P, E L, N F, J R$ conceived and performed experiments and assisted with writing the manuscript. CAJ, NM, DM and RLS conceived experiments and assisted with writing the manuscript. $\mathrm{BO}, \mathrm{AF}$ and $\mathrm{TAC}$ provided unique research materials. All authors read and approved the final manuscript

\section{Competing interests}

The authors declare that they have no competing interests.

Received: 7 September 2011 Accepted: 5 February 2012 Published: 5 February 2012

\section{References}

1. Wang J, Bixby JL: Receptor tyrosine phosphatase-delta is a homophilic, neurite-promoting cell adhesion molecular for CNS neurons. Mol Cell Neurosci 1999, 14:370-384.

2. Giefing M, Zemke N, Brauze D, Kostrzewska-Poczekaj M, Luczak M, Szaumkessel M, Pelinska K, Kiwerska K, Tonnies H, Grenman R, et al: High resolution ArrayCGH and expression profiling identifies PTPRD and PCDH17/PCH68 as tumor suppressor gene candidates in laryngeal squamous cell carcinoma. Genes Chromosomes Cancer 2011, 50:154-166.

3. Purdie KJ, Lambert SR, Teh MT, Chaplin T, Molloy G, Raghavan M, Kelsell DP, Leigh IM, Harwood CA, Proby CM, Young BD: Allelic imbalances and microdeletions affecting the PTPRD gene in cutaneous squamous cell carcinomas detected using single nucleotide polymorphism microarray analysis. Genes Chromosomes Cancer 2007, 46:661-669.

4. Sato M, Takahashi K, Nagayama K, Arai Y, Ito N, Okada M, Minna JD, Yokota J, Kohno T: Identification of chromosome arm $9 p$ as the most frequent target of homozygous deletions in lung cancer. Genes Chromosomes Cancer 2005, 44:405-414.

5. Stallings RL, Nair P, Maris JM, Catchpoole D, McDermott M, O'Meara A, Breatnach F: High-resolution analysis of chromosomal breakpoints and genomic instability identifies PTPRD as a candidate tumor suppressor gene in neuroblastoma. Cancer Res 2006, 66:3673-3680.

6. Veeriah S, Brennan C, Meng S, Singh B, Fagin JA, Solit DB, Paty PB, Rohle D, Vivanco I, Chmielecki J, et al: The tyrosine phosphatase PTPRD is a tumor suppressor that is frequently inactivated and mutated in glioblastoma and other human cancers. Proc Natl Acad Sci USA 2009, 106:9435-9440.

7. Zhao X, Weir BA, LaFramboise T, Lin M, Beroukhim R, Garraway L, Beheshti J, Lee JC, Naoki K, Richards WG, et al: Homozygous deletions and chromosome amplifications in human lung carcinomas revealed by single nucleotide polymorphism array analysis. Cancer Res 2005, 65:5561-5570.

8. Stark M, Hayward N: Genome-wide loss of heterozygosity and copy number analysis in melanoma using high-density single-nucleotide polymorphism arrays. Cancer Res 2007, 67:2632-2642.

9. Kohno T, Otsuka A, Girard L, Sato M, Iwakawa R, Ogiwara H, SanchezCespedes M, Minna JD, Yokota J: A catalog of genes homozygously deleted in human lung cancer and the candidacy of PTPRD as a tumor suppressor gene. Genes Chromosomes Cancer 2010, 49:342-352.

10. Nair P, De Preter K, Vandesompele J, Speleman F, Stallings RL: Aberrant splicing of the PTPRD gene mimics microdeletions identified at this locus in neuroblastomas. Genes Chromosomes Cancer 2008, 47:197-202.

11. Solomon DA, Kim JS, Cronin JC, Sibenaller Z, Ryken T, Rosenberg SA, Ressom $\mathrm{H}$, Jean W, Bigner D, Yan $\mathrm{H}$, et al: Mutational inactivation of PTPRD in glioblastoma multiforme and malignant melanoma. Cancer Res 2008, 68:10300-10306.

12. Mokarram P, Kumar K, Brim H, Naghibalhossaini F, Saberi-firoozi M, Nouraie M, Green R, Lee E, Smoot DT, Ashktorab H: Distinct high-profile methylated genes in colorectal cancer. PLoS One 2009, 4:e7012.

13. Brodeur GM: Neuroblastoma: biological insights into a clinical enigma. Nat Rev Cancer 2003, 3:203-216.
14. Seeger RC, Brodeur GM, Sather H, Dalton A, Siegel SE, Wong KY, Hammond D: Association of multiple copies of the $\mathrm{N}$-myc oncogene with rapid progression of neuroblastomas. N Engl J Med 1985, 313:1111-1116.

15. Shang X, Burlingame SM, Okcu MF, Ge N, Russell HV, Egler RA, David RD, Vasudevan SA, Yang J, Nuchtern JG: Aurora A is a negative prognostic factor and a new therapeutic target in human neuroblastoma. Mol Cancer Ther 2009, 8:2461-2469.

16. Pulido R, Serra-Pages C, Tang M, Streuli M: The LAR/PTP delta/PTP sigma subfamily of transmembrane protein-tyrosine-phosphatases: multiple human LAR, PTP delta, and PTP sigma isoforms are expressed in a tissue-specific manner and associate with the LAR-interacting protein LIP.1. Proc Natl Acad Sci USA 1995, 92:11686-11690.

17. Woodings JA, Sharp SJ, Machesky LM: MIM-B, a putative metastasis suppressor protein, binds to actin and to protein tyrosine phosphatase delta. Biochem J 2003, 371:463-471.

18. Crane R, Gadea B, Littlepage L, Wu H, Ruderman JV: Aurora A, meiosis and mitosis. Biol Cell 2004, 96:215-229.

19. Pulido R, Krueger NX, Serra-Pages C, Saito H, Streuli M: Molecular characterization of the human transmembrane protein-tyrosine phosphatase delta. Evidence for tissue-specific expression of alternative human transmembrane protein-tyrosine phosphatase delta isoforms. $J$ Biol Chem 1995, 270:6722-6728.

20. Ferrari S, Marin O, Pagano MA, Meggio F, Hess D, El-Shemerly M, Krystyniak A, Pinna LA: Aurora-A site specificity: a study with synthetic peptide substrates. Biochem J 2005, 390:293-302.

21. Otto T, Horn S, Brockmann M, Eilers U, Schuttrumpf L, Popov N, Kenney AM, Schulte JH, Beijersbergen R, Christiansen $H$, et al: Stabilization of N-Myc is a critical function of Aurora A in human neuroblastoma. Cancer Cell 2009, 15:67-78.

22. Ohashi S, Sakashita G, Ban R, Nagasawa M, Matsuzaki H, Murata $Y$, Taniguchi H, Shima H, Furukawa K, Urano T: Phospho-regulation of human protein kinase Aurora-A: analysis using anti-phospho-Thr288 monoclonal antibodies. Oncogene 2006, 25:7691-7702.

23. Kitajima S, Kudo Y, Ogawa I, Tatsuka M, Kawai H, Pagano M, Takata T: Constitutive phosphorylation of aurora-a on ser51 induces its stabilization and consequent overexpression in cancer. PLoS One 2007, 2: e944.

24. Murphy DM, Buckley PG, Bryan K, Das S, Alcock L, Foley NH, Prenter S, Bray I, Watters KM, Higgins D, Stallings RL: Global MYCN transcription factor binding analysis in neuroblastoma reveals association with distinct E-box motifs and regions of DNA hypermethylation. PLOS One 2009, 4:e8154.

25. Murphy DM, Buckley PG, Bryan K, Watters KM, Koster J, van Sluis P, Molenaar J, Versteeg R, Stallings RL: Dissection of the oncogenic MYCN transcriptional network reveals a large set of clinically relevant cell cycle genes as drivers of neuroblastoma tumorigenesis. Mol Carcinog 2011, 50:403-411.

26. van der Vaart B, Manatschal C, Grigoriev I, Olieric V, Gouveia SM, Bjelic S, Demmers J, Vorobjev I, Hoogenraad CC, Steinmetz MO, Akhmanova A: SLAIN2 links microtubule plus end-tracking proteins and controls microtubule growth in interphase. J Cell Biol 2011, 193:1083-1099.

27. Ferrari S: Protein kinases controlling the onset of mitosis. Cell Mol Life Sci 2006, 63:781-795.

28. Lens SM, Voest EE, Medema RH: Shared and separate functions of pololike kinases and aurora kinases in cancer. Nat Rev Cancer 2010, 10:825-841.

29. Macurek $L$, Lindqvist $A$, Lim $D$, Lampson MA, Klompmaker $R$, Freire $R$, Clouin C, Taylor SS, Yaffe MB, Medema RH: Polo-like kinase-1 is activated by aurora A to promote checkpoint recovery. Nature 2008, 455:119-123.

30. Ackermann S, Goeser F, Schulte JH, Schramm A, Ehemann V, Hero B, Eggert A, Berthold F, Fischer M: Polo-like kinase 1 is a therapeutic target in high-risk neuroblastoma. Clin Cancer Res 2011, 17:731-741.

31. Maris JM, Morton CL, Gorlick R, Kolb EA, Lock R, Carol H, Keir ST, Reynolds CP, Kang MH, Wu J, et al: Initial testing of the aurora kinase A inhibitor MLN8237 by the Pediatric Preclinical Testing Program (PPTP). Pediatr Blood Cancer 2010, 55:26-34.

32. Carol H, Boehm I, Reynolds CP, Kang MH, Maris JM, Morton CL, Gorlick R, Kolb EA, Keir ST, Wu J, et al: Efficacy and pharmacokinetic/ pharmacodynamic evaluation of the Aurora kinase A inhibitor MLN8237 
doi:10.1186/1476-4598-11-6

Cite this article as: Meehan et al:: Protein tyrosine phosphatase receptor

delta acts as a neuroblastoma tumor suppressor by destabilizing the aurora kinase a oncogene. Molecular Cancer 2012 11:6.

Submit your next manuscript to BioMed Central and take full advantage of:

- Convenient online submission

- Thorough peer review

- No space constraints or color figure charges

- Immediate publication on acceptance

- Inclusion in PubMed, CAS, Scopus and Google Scholar

- Research which is freely available for redistribution

Submit your manuscript at 